\title{
MicroRNAs serve as a bridge between oxidative stress and gastric cancer (Review)
}

\author{
TIANHE HUANG ${ }^{1}$, FENG WANG-JOHANNING ${ }^{2}$, FULING ZHOU ${ }^{3}$, HERBERT KALLON ${ }^{4}$ and YONGCHANG WEI ${ }^{5}$ \\ ${ }^{1}$ Department of Clinical Oncology, The First Affiliated Hospital, Medical School of Xi'an Jiaotong University \\ Xi'an, Shaanxi 710061, P.R. China; ${ }^{2}$ Viral Oncology Program, SRI International, \\ Menlo Park, CA, USA; ${ }^{3}$ Department of Clinical Hematology, The Second Affiliated Hospital, \\ Medical School of Xi'an Jiaotong University, Xi'an, Shaanxi 710004; ${ }^{4}$ College of Medicine, \\ Xi'an Jiaotong University, Xi'an, Shaanxi 710061; ${ }^{5}$ Department of Radiation and Medical Oncology, \\ Zhongnan Hospital of Wuhan University, Wuhan, Hubei 430071, P.R. China
}

Received June 29, 2016; Accepted August 24, 2016

DOI: $10.3892 /$ ijo.2016.3686

Correspondence to: Professor Yongchang Wei, Department of Radiation and Medical Oncology, Zhongnan Hospital of Wuhan University, 169 East Lake Road, Wuhan, Hubei 430071, P.R. China E-mail: weiyongchang8@163.com

Abbreviations: GC, gastric cancer; ROS, reactive oxygen species; OS, oxidative stress; miRs, microRNAs; 8-OHdG, 8-hydroxy2'-deoxyguanosine; hOGG1, human oxoguanine glycosylase 1; XOD, xanthine oxidase; $\mathrm{O}_{2}^{-{ }^{-}}$, superoxide; ${ }^{\circ} \mathrm{OH}$, hydroxide; $\mathrm{H}_{2} \mathrm{O}_{2}$, hydrogen peroxide; MAPK, mitogen-activated protein kinases; HIF-1 $\alpha$, hypoxiainducible factor 1 $\alpha$; Cav-1, caveolin-1; EMT, epithelial-mesenchymal transition; VEGF, vascular endothelial growth factor; Akt, protein kinase-B; mTOR, mammalian target of rapamycin; NRF2, NF-E2related factor; ARE, antioxidant response element; NF- $\kappa \mathrm{B}$, nuclear factor- $\kappa \mathrm{B}$; Hp, Helicobacter pylori; SMOX, spermine oxidase; EFGR, epidermal growth factor receptor; CASK, calmodulin-dependent serine protein kinase; STMN1, oncoprotein 18 or metablastin; DIMT1, demethyladenosine transferease 1; 3'-UTR, 3' untranslated region; IPF, idiopathic pulmonary fibrosis; ER, endoplasmic reticulum; Cbl, Casitas-B-lineage lymphoma; PDCD4, programmed cell death protein 4; PTEN, phosphatase and tension homolog deleted on chromosome 10; CDK, cyclin-dependent kinase; CDI, cyclin-dependent kinase inhibitor; TGF- $\beta$, transforming growth factor- $\beta$; Mcl- 1 , myeloid cell leukemia 1; Bcl-xL, BCL2-like 1; ZNF24, zinc finger transcription factor 24; RUNX3, runt-related transcription factor 3; ZBTB7A, zinc finger and BTB domain containing 7A; PRL-3, phosphatase of regenerating liver-3; p27, Kip1; RELA, v-rel avian reticuloendotheliosis viral oncogene homolog A; FOS, FBJ osteosarcoma oncogene; CREB1, cAMP responsive element binding protein 1; HS3ST2, heparan sulfate (glucosamine) 3-O-sulfotransferase 2; RDX, radixin; PHF10, PHD finger protein 10; SPHK1, sphingosine kinase 1; ILK, integrinlinked kinase; $\mathrm{CDH} 2$, cadherin 2; STAT3, signal transducer and activator of transcription 3; RECK, reversion-inducing-cysteine-rich protein with kazal motifs; TPM1, tropomyosin $1(\alpha)$; CDX1, caudal type homeobox 1; EPB41 L3, erythrocyte membrane protein band 4.1-like 3; DNMT, DNA methyltransferase; EZH2, zeste homolog 2; COBRA, combined bisulfiterestriction analysis; H3K27, histone H3 lysine 27; H3K4, histone 3 lysine 4; HDACs, histone deacetylases

Key words: microRNAs, oxidative stress, reactive oxygen species, tumorigenesis, gastric cancer
Abstract. Gastric cancer (GC) remains one of the most prevalent tumors worldwide and affects human health due to its high morbidity and mortality. Mechanisms underlying occurrence and development of GC have been widely studied. Studies have revealed reactive oxygen species (ROS) generated by cells under oxidative stress (OS) are involved in gastric tumorigenesis, and modulate expression of microRNAs (miRs). As such, miRs have been shown to be associated with OS-related GC. Given the association of OS and miRs in development of $\mathrm{GC}$, this review aims to summarize the relationship between miRs and OS and their role in GC development. Serving as a link between OS and GC, miRs may offer new approaches for gaining a more in-depth understanding of mechanisms of GC and may lead to the identification of new therapeutic approaches against GC.

\section{Contents}

1. Introduction

2. OS is involved in the tumorigenesis of GC through ROS

3. OS modulates expression of miRs

4. Alteration of miRs participates in tumorigenesis of GC

5. miRs serve as a link between OS and GC

6. Conclusion

\section{Introduction}

Gastric cancer (GC) is one of the most common types of cancers worldwide. Each year, almost one million people are newly diagnosed with GC, and over 700,000 people die of GC (1). Due to high prevalence and death rate, GC remains a tremendous threat to word health. An increasing body of evidence shows that patients with GC experience high levels of OS, which contribute to progression of GC. Markers of OS, such as 8-hydroxy-2'-deoxyguanosine (8-OHdG), human oxoguanine glycosylase 1 (hOGG1) and xanthine oxidase (XOD) are aberrant in GC (2). Due to redox imbalance, OS 
participates in progression of GC by affecting expression of critical effectors, including miRs $(3,4)$. miRs are small non-coding RNAs that modulate gene expression by either inhibiting mRNA translation or inducing mRNA degradation at post-transcriptional level (5). miRs have been relevant to promotion or suppression of tumorigenesis in GC and are implicated in cell growth, differentiation, invasion, metastasis, and apoptosis in GC (6). Additionally, OS gives rise to abnormal expression of miRs in various types of diseases, including cancers (7-9). Although function of miRs has been extensively investigated in GC, whether miRs may be associated with or serve as a link between OS and GC remains unknown. In this review, we focus on roles of OS in GC, OS-induced miRs in GC, and roles of dysfunctional miRs in $\mathrm{GC}$ to gain further understanding of the association of OS and miRs in gastric tumorigenesis.

\section{OS is involved in the tumorigenesis of GC through ROS}

OS, which refers to redox imbalance with excessive production of ROS exceeding the scavenging ability of human body (10), has been associated with pathophysiology of both solid tumors and hematological malignant diseases $(11,12)$. ROS, including superoxide $\left(\mathrm{O}_{2}^{\circ}\right)$, hydroxide $\left({ }^{\circ} \mathrm{OH}\right)$, and hydrogen peroxide $\left(\mathrm{H}_{2} \mathrm{O}_{2}\right)$, lead to damage to cell membrane, protein, and DNA (13). Physiologically, glutathione peroxidase (GPX), superoxide dismutase (SOD), and catalase could scavenge ROS to preserve redox homeostasis. ROS also contribute to cell apoptosis by regulating p38 $\alpha$ mitogen-activated protein kinases (MAPK) (14). More importantly, ROS stimulate the NF-E2-related factor (NRF2)-mediated activation of an antioxidant response element (ARE) to protect cells again OS (15). Nevertheless, under OS, excessive ROS in cells could damage tissues, leading to tumorigenesis, particularly in the gastrointestinal tract.

For GC, in both human and mouse, ROS are actuated factors in gastric carcinogenesis. In human GC, ROS are dysregulated in serum and tissue samples (16). In Helicobacter pylori (Hp) along with N-methyl-N'-nitro-N'-nitrosoguanidine (MNNG) triggered mouse GC models, ROS activated downstream targets including P53, Wnt, Ras, mTOR to initiate gastric carcinogenesis $(17,18)$. Hypoxia leads to producing ROS, which prevent degradation of hypoxia-inducible factor $1 \alpha(\mathrm{HIF}-1 \alpha)(19)$. As a transcription factor, accumulation of HIF-1 $\alpha$ is able to modulate expression of various genes, which are important in gastric tumorigenesis. For example, HIF-1 $\alpha$ attenuates expression of caveolin-1 (Cav-1), which can induce the epithelial-mesenchymal transition (EMT) in GC through regulation of E-cadherin (20). HIF-1 $\alpha$ also activates vascular endothelial growth factor (VEGF) pathway to enhance angiogenesis in GC (21). In contrast, ROS act as a signaling molecule and trigger essential signaling pathways indispensible to promoting the occurrence and development of GC. As second messenger, ROS are well known to activate tyrosine kinases and MAPK, leading to cell proliferation (22), as well as trigger activation of protein kinase-B (Akt)/ mammalian target of rapamycin (mTOR) signaling pathway to promote GC cell proliferation (23). Moreover, ROS have been found to stimulate nuclear factor $-\kappa \mathrm{B}(\mathrm{NF}-\kappa \mathrm{B})$ to promote $\mathrm{GC}$ invasion $(24,25)$.
In addition, OS exerts a crucial role in $\mathrm{Hp}$-induced diseases. Hp infection is a recognized risk factor in pathogenesis of gastric disease, such as chronic atrophic gastritis, gastric ulcer, and GC. Chaturvedi et al showed that Hp activation of spermine oxidase (SMOX) in gastric epithelial cells results in OS (26). OS causes damage to biological structures such as proteins, carbohydrates, lipids, and nucleic acids (27). DNA damage promotes activation of the epidermal growth factor receptor (EFGR) signaling pathway and mutations of tumor-suppressor genes, such as p53 and calcium/calmodulindependent serine protein kinase (CASK) $(28,29)$, which are critical initial events in gastric carcinogenesis. Additionally, Hp infection also induces changes in expression of miRs in GC. For example, miR-328 is a well-studied miR involved in Hp-induced GC. Ishimoto et al demonstrated that miR-328 is downregulated in Hp-infected gastritis (30). Analysis of expression of miR-328 in GC, yielded a result similar to that obtained in gastritis. A low level of miR-328 activates CD44, a target of miR-328, to promote GC stem cell differentiation (4). Effect of $\mathrm{Hp}$ infection on miR-328 expression could be mimicked by $\mathrm{H}_{2} \mathrm{O}_{2}$. Therefore, miR-328 may be a specific miR that triggers development of Hp-induced GC by ROS. However, these researchers did not provide an explanation for downregulation of miR-328 in Hp-infected GC. Indeed, previous studies have demonstrated that Hp induced expression miR-210 by regulating methylation of miR-210, thereby increasing proliferation of gastric epithelial cells through suppressing oncoprotein 18 or metablastin (STMN1) and dimethyladenosine transferase 1 (DIMT1) (31). Therefore, Hp infection may alter expression of miRs through ROS-mediated methylation of gene promoter region. Hp-induced OS, which interferes with methylation of miRs, may account for part of the mechanism underlying the initiation of GC. In studies of effect of radiation on GC cells, radiation, which acts similarly to $\mathrm{OS}$, also leads to production of ROS (32).

In conclusion, hypoxia, $\mathrm{Hp}$ infection, and radiation are capable of triggering cellular OS, and excessive ROS lead to the inhibition of anti-oncogenes such as p53, and the activation of tumorigenesis-associated signaling pathways, which contribute to occurrence and development of GC (Fig. 1).

\section{OS modulates expression of miRs}

Since the first miR, lin-4 (3), was discovered, an increasing number of studies have focused on these small non-coding RNAs. miRs regulate gene expression by completely or incompletely binding to $3^{\prime}$ untranslated region (3'-UTR) of target messenger RNAs. miRs are demonstrated to modulate expression of target genes. However, the crucial factor affecting expression of miRs has not been identified. OS can influence gene expression by regulating their methylation status of genes $(33,34)$. Whether OS can affect the expression of miRNAs remains an open question.

As mentioned previously, under OS, ROS are produced and play a key role under pathological conditions. Hydrogen peroxide is widely used in experiments to simulate the effect of OS in cell lines and results in the abnormal expression of miRs in numerous diseases, including vitiligo, idiopathic pulmonary fibrosis (IPF), and most cancers. ROS induced miR-25 has been shown to enhance degeneration of melanocytes in 


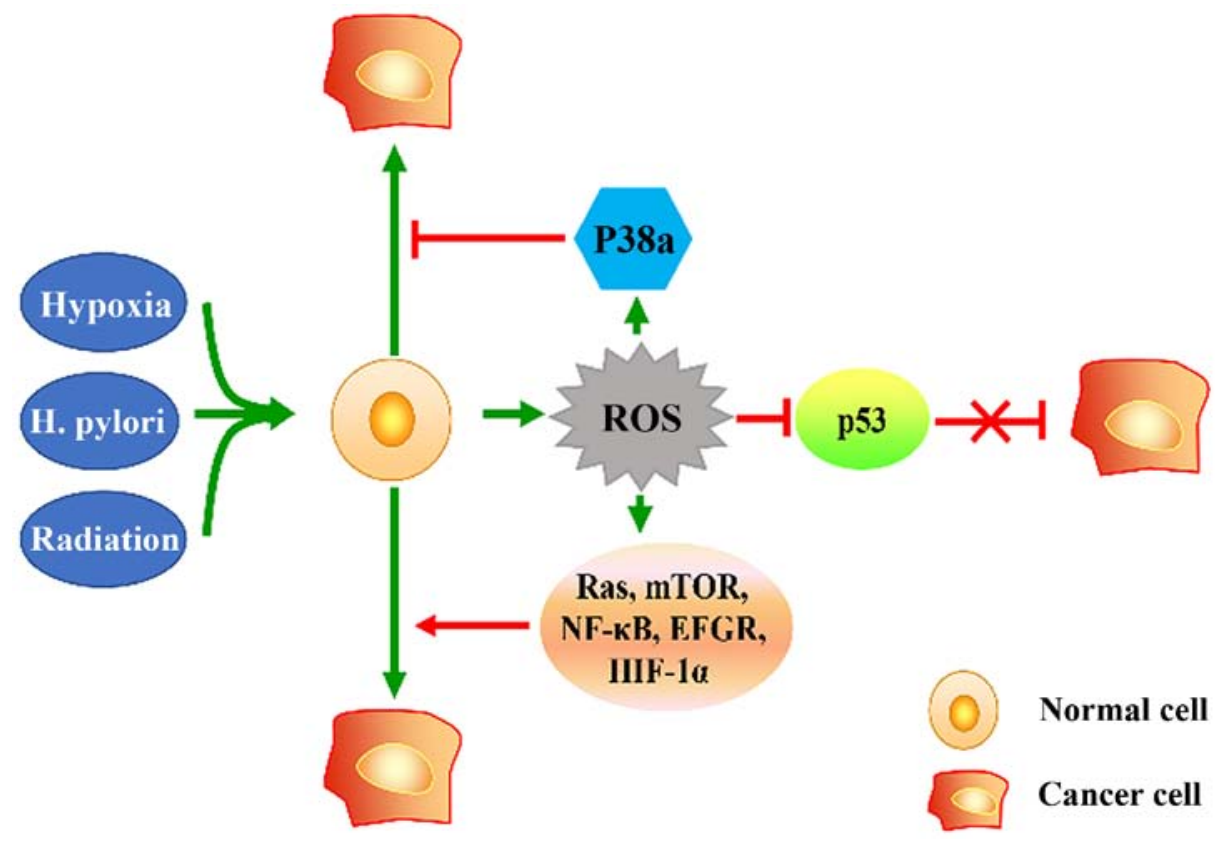

Figure 1. Effect of OS on gastric cells. Hypoxia, Hp infection, and radiation lead to OS. Product of OS, ROS activate p38 $\alpha$ in response to OS to act as an adaptive change for the prevention of tumorigenesis. Excessive ROS lead to the activation of Ras, mTOR, NF-kB, EFGR, and HIF-1 $\alpha$ to trigger development of GC, and the mutation of P53, loss of expression of which also contributes to gastric tumorigenesis.

vitiligo (35). Elevated levels of miR-9-5p has been confirmed to be influenced by ROS both in vivo and in vitro. In specimens of patients with IPF, expression of miR-9-5p has been associated with ROS and is upregulated in human fetal lung fibroblasts treated with hydrogen peroxide (36). Independently, endoplasmic reticulum (ER) stress can be caused by hypoxia, failure of protein maturation, or degradation (37). Induced by ER stress, expression of miR-17, $-34 \mathrm{a},-96$, and $-125 \mathrm{~b}$ and the consequent reduction in the translation of proapoptotic caspase-2 (38). Additionally, exposure of cells to arsenic triggers upregulation of miR-663, miR-222, and miR-638 (39).

ROS exhibit their characteristics in intervening in expression of miRs in cancers. Similarly, placing cells under hypoxic condition is a common way to test the effect of OS on cancer cell lines. In breast and prostate cancer cells, miR-196b could be restrained by hypoxia (40). In bladder cancer cells, hypoxia could induce expression of miR-145 (41). Additionally, in response to ionizing radiation, ROS were stated to upregulate miR-193a-3p and miR-30e (42,43). miR-193a-3p has been demonstrated to lead to apoptosis by targeting Mcl-1, and miR-30e promote glioma cell invasion through EGFR stabilization by directly targeting Casitas-B-lineage lymphoma (Cbl)-b.

In GC, miR-382 was upregulated by hypoxia and participate in hypoxia-induced angiogenesis of GC (44). As discussed previously, Hp infection alters expression of miRs, such as miR-328 and miR-210, through ROS. Moreover, our team and other researchers focused on activities of miR-21 in GC and concluded that ROS give rise to progression of GC through dysfunction of miR-21 $(45,46)$. Both programmed cell death protein 4 (PDCD4) and phosphatase and tension homolog deleted on chromosome 10 (PTEN) have been confirmed to be targets of miR-21. The silencing of miR-21 with its inhibitor AC1 MMYR2 reverse the effect of EMT accompanied by suppression of proliferation and invasion of GC (47). We also sought to identify other miRs affected by $\operatorname{ROS}\left(\mathrm{O}_{2}^{-{ }^{-},}, \mathrm{OH}\right)$; but few studies have examined the relationship of $\mathrm{O}_{2}{ }^{\circ}$ and ${ }^{\circ} \mathrm{OH}$ with miRs because $\mathrm{H}_{2} \mathrm{O}_{2}$ is easy to use and detect in experiments. However, we found that enzymes catalyzing $\mathrm{O}_{2}{ }^{\circ}$ and ${ }^{\circ} \mathrm{OH}$ are positively correlated with the expression of some miRs, such as miR-200b (48). In fact, the role of OS in regulating the expression of miRs has been widely studied. Selected miRs responsive to OS are shown in Table I. In summary, under OS, product of OS in cells mediate expression of miRs by different mechanisms and participate in progression of various types of diseases, including GC. The detailed mechanism will be discussed in part 5 .

\section{Alteration of miRs participates in tumorigenesis of GC}

It is well known that miRs are differentially expressed in different types of cancers and are implicated in processes of carcinogenesis, such as cell proliferation, angiogenesis, invasion, and metastasis. miRs have been identified to predict prognosis of GC patients. For example, selective overexpression of miR-25 in advanced GC indicated poor survival (58) and downregulation of miR-451 was associated with worse prognosis of GC patients (59). miRs may regulate the cell cycle through direct interaction with key regulators, such as cyclin, cyclin-dependent kinase (CDK), and cyclin-dependent kinase inhibitor (CDI). Specifically, cyclins D1 and E1 are targets of miR-16, and low levels of miR-16 contribute to development of colon cancer (60). In leukemia, CDK2 has been found to be a target gene of miR-638, and depression of miR-638 was found to be crucial for differentiation and proliferation of leukemia cells (61). With regard to miR-related cancer invasion and metastasis, miR-367 has been shown to promote invasion by downregulating Smad7 and to stimulate the EMT through 
Table I. OS regulates expression of miRs.

\begin{tabular}{|c|c|c|c|c|}
\hline Items & miRs & Expression & Induced by & Refs. \\
\hline \multirow[t]{3}{*}{ Gastric cancer } & $\operatorname{miR}-370$ & Downregulated & H.pylori & $(49)$ \\
\hline & miR-203 & Downregulated & H.pylori & $(28)$ \\
\hline & miR-328 & Downregulated & H. pylori, $\mathrm{H}_{2} \mathrm{O}_{2}$ & $(4,50)$ \\
\hline Lung fibrosis & $\operatorname{miR}-9-5 p$ & Upregulated & $\mathrm{H}_{2} \mathrm{O}_{2}$ & $(36)$ \\
\hline Vitiligo & $\operatorname{miR}-25$ & Upregulated & $\mathrm{H}_{2} \mathrm{O}_{2}$ & $(35)$ \\
\hline Mesenchymal stem cells & miR-181a & Upregulated & $\mathrm{H}_{2} \mathrm{O}_{2}$ & $(51)$ \\
\hline Endothelial innate immune response & $\operatorname{miR}-92 \mathrm{a}$ & Upregulated & $\mathrm{H}_{2} \mathrm{O}_{2}$ & $(52)$ \\
\hline MELAS syndrome & microRNA-9/9* & Upregulated & $\mathrm{H}_{2} \mathrm{O}_{2}$ & $(53)$ \\
\hline $\begin{array}{l}\text { Cardiac muscle, vascular } \\
\text { smooth muscle cells }\end{array}$ & miR-30 family & Downregulated & $\mathrm{H}_{2} \mathrm{O}_{2}$ & $(54)$ \\
\hline \multirow[t]{2}{*}{ Glioma } & $\operatorname{miR}-193 a-3 p$ & Upregulated & Radiation & $(42)$ \\
\hline & miR-30e & Upregulated & Radiation & $(43)$ \\
\hline Human bronchial epithelial cells & $\mathrm{miR}-15 \mathrm{~b} / 16-2$ & Upregulated & Radiation & $(55)$ \\
\hline Nasopharyngeal carcinoma & miR-504 & Upregulated & Radiation & $(56)$ \\
\hline \multirow[t]{2}{*}{ Bladder cancer } & $\operatorname{miR}-769-3 p$ & Downregulated & Hypoxia & $(57)$ \\
\hline & $\operatorname{miR}-145$ & Upregulated & Hypoxia & $(41)$ \\
\hline Breast and prostate cancer & miRNA-196b & Downregulated & Hypoxia & $(40)$ \\
\hline
\end{tabular}

activation of the transforming growth factor- $\beta$ (TGF- $\beta$ ) signaling pathway (62). Moreover, in chondrosarcoma, miR-200b directly repress VEGF to inhibit angiogenesis (63). In cancers, most decreased miRs show activities as tumor-suppressor gene, and miR mimics prevent development of cancer. Conversely, high levels of miRs mainly act as oncogene and promote tumorigenesis. Following this review of role of miRs in cancer, we will concentrate our discussion on roles of miRs in GC.

In $\mathrm{GC}$, numerous miRNAs have been identified, and dysfunction of these miRs promotes progression of GC. Expression of miRs has been found to be either increased or decreased in both GC tissues and cell lines. For example, miR-133b/a-3p has been ascertained to be reduced in primary GC tissues and two GC cell lines, namely SGC7901 and MNK45 (64). Using TargetScan database and luciferase assay, myeloid cell leukemia 1 (Mcl-1) and BCL2-like 1 (Bcl-xL) were shown to be targets of miR-133b/a-3p. Furthermore, using mouse tumor-bearing model and cell lines, miR-133b/ $a-3 p$ has been ascertained to inhibit tumor growth. Similarly, miR-940 has been shown to promote tumor cell invasion and metastasis by interacting with zinc finger transcription factor 24 (ZNF24) in GC (65); miR-130a and miR-495 have been confirmed to increase cell proliferation and angiogenesis by targeting runt-related transcription factor 3 (RUNX3) in GC (66); miR-544a could induce the EMT by sensitizing Wnt signaling pathway in GC (67); and a lower miR-100 level is associated with lymphatic metastasis by targeting zinc finger and BTB domain containing 7A (ZBTB7A) (68). In fact, miRs have been widely investigated in GC. Studies of miRs in GC almost follow the methods described above. A list of miRs in GC, including their expression types, targets, and functions in gastric cancer is presented in Table II. Similar to role of miRs in other types of cancers, increased levels of miRs in GC act as oncogenes and reduced levels of miRs act as tumor suppressor genes. In general, molecules downstream of these miR targets are key factors involved in the signaling pathways in GC. For example, miR-141 is capable of regulating EGFR2 signaling pathway to affect proliferation of GC cells (69), and miR-495 can influence migration and invasion by action of phosphatase on regenerating liver-3 (PRL-3) (70); and Kip1 (p27), acting as a CDK, is the direct target of miR-196a, and a lower level of Kip1 due to inhibition by miR-196a leads to the proliferation of GC cells (71).

Few studies have evaluated screening or diagnostic value of miRs in gastric juice and serum as a noninvasive method for GC treatment. The miR-21 and miR-106a levels in gastric juice were lower in GC than in benign gastric diseases, and showed a specificity of 0.969 and 0.871 , respectively, for the identification of GC compared with benign gastric diseases (88). In GC, serum level of miR-203 is significantly lower compared with the control. Similar to its value in GC tissue, lower serum levels of miR-203 reflect an advanced clinical stage and poor overall survival, which is consistent with well-studied activity of miR-203 in inhibiting the EMT $(89,90)$.

Despite the roles of these miRs, few studies have compared levels of miR in both tissue and serum from time of occurrence of morbidity to time of death of GC patients. This question is challenging for several reasons, such as the fact that we may not know when GC begins and cannot obtain adequate tissue samples once tumor progresses. By studying changes in the levels of miRs in body fluids, it may be possible for us to identify specific markers for GC.

\section{5. miRs serve as a link between OS and GC}

As discussed above, product of OS is involved in development of GC, and production of OS thus leads to an abnormal 
Table II. Alteration, function, and target(s) of some miRs in gastric cancer.

\begin{tabular}{|c|c|c|c|c|}
\hline miRs & Expression & Target (s) & Function & Refs. \\
\hline miR-7 & Downregulated & RELA, FOS & Inhibition of proliferation & $(72)$ \\
\hline $\operatorname{miR}-100$ & Downregulated & ZBTB7A & Inhibition of proliferation and metastasis & $(68)$ \\
\hline miR-141 & Downregulated & EGFR2 & Inhibition of proliferation & $(69)$ \\
\hline $\operatorname{miR}-182$ & Downregulated & CREB1 & Inhibition of proliferation & $(73,74)$ \\
\hline $\operatorname{miR}-100$ & Downregulated & HS3ST2 & Inhibition of proliferation & $(75)$ \\
\hline miR-409-3p & Downregulated & RDX, PHF10 & Inhibition of proliferation, invasion, and metastasis & $(76,77)$ \\
\hline $\operatorname{miR}-124$ & Downregulated & SPHK1 & Inhibition of proliferation & $(78)$ \\
\hline $\operatorname{miR}-495 / 551 \mathrm{a}$ & Downregulated & PRL-3 & Inhibition of migration and invasion & $(70)$ \\
\hline miR-625 & Downregulated & ILK & Inhibition of invasion and metastasis & (79) \\
\hline $\operatorname{miR}-145$ & Downregulated & $\mathrm{CDH} 2$ & Inhibition of invasion, metastasis, and angiogenesis & $(80)$ \\
\hline miR-874 & Downregulated & STAT3 & Inhibition of angiogenesis & $(81)$ \\
\hline $\operatorname{miR}-21$ & Upregulated & $\begin{array}{l}\text { RECK, PTEN, PDCD4, } \\
\text { TPM1, Maspin }\end{array}$ & Promotion of proliferation and metastasis & $(82-84)$ \\
\hline $\operatorname{miR}-301 \mathrm{a}$ & Upregulated & RUNX3 & Promotion of proliferation and metastasis & $(85)$ \\
\hline miR-196a & Upregulated & KIP1 & Promotion of proliferation & $(71)$ \\
\hline $\operatorname{miR}-296-5 p$ & Upregulated & CDX1 & Promotion of proliferation & $(86)$ \\
\hline $\operatorname{miR}-223$ & Upregulated & EPB41L3 & Promotion of invasion and metastasis & $(87)$ \\
\hline
\end{tabular}

Table III. Expression of miRs is modulated by epigenetic factors in GC.

\begin{tabular}{|c|c|c|c|c|}
\hline miRs & Expression & Methylation status & Modulated by & Refs. \\
\hline $\mathrm{miR}-200 \mathrm{~b} / \mathrm{a} / 429$ & Downregulated & Hypermethylation & DNMT1/EZH2 & (95) \\
\hline let-7 & Downregulated & Hypermethylation, H3K27 trimethylation & DNMT3B/EZH2 & $(101)$ \\
\hline $\operatorname{miR}-99 a / 449 a$ & Downregulated & H3K27 trimethylation & EZH2 & $(102)$ \\
\hline $\operatorname{miR}-124 a-1 / 2 / 3$ & Downregulated & Hypermethylation & $\mathrm{NA}^{\mathrm{a}}$ & $(100)$ \\
\hline miR-139 & Downregulated & Hypermethylation & NA & $(103)$ \\
\hline $\operatorname{miR}-490-3 p$ & Downregulated & Hypermethylation, $\mathrm{H} 3 \mathrm{~K} 4$ trimethylation & NA & $(104)$ \\
\hline miR-335 & Downregulated & Hypermethylation & NA & $(105)$ \\
\hline $\mathrm{miR}-34 \mathrm{~b} / \mathrm{c}$ & Downregulated & Hypermethylation & NA & $(106)$ \\
\hline $\operatorname{miR}-200 b$ & Downregulated & Hypermethylation & NA & $(107)$ \\
\hline miR-149 & Downregulated & Hypermethylation & NA & (94) \\
\hline $\operatorname{miR}-196 b$ & Upregulated & Hypomethylation & NA & $(99)$ \\
\hline miR-127 & Upregulated & Demethylation & NA & (100) \\
\hline
\end{tabular}

${ }^{\mathrm{a}} \mathrm{NA}$, not available.

expression profile of miRs in diseases including cancers. Importantly, miRs can either promote or suppress tumorigenesis in GC. Whether miRs may serve as a link between OS and GC remains unclear.

To the best of our knowledge, epigenetic factors play a crucial role in carcinogenesis during OS. ROS contribute to methylation of miR genes, subsequently resulting in development of cancer by influencing expression of miRs, such as miR-145-5p, miR-362-3p, miR-329, miR-199, and miR-125 (91-93). Frequently, ROS increase methylation of miRs, which play roles of tumor suppressor genes. For example, the hypermethylation of miR-199a and miR-125b induced by ROS is modulated by DNA methyltransferase (DNMT) 1, which downregulated these two miRs in an ovarian cancer cell line (93).

In Hp-induced GC, a decreased expression of miR-328 is mediated by ROS (4). Expression of miR-210 and miR-149 is thought to be modulated by methylation in Hp-positive human gastric biopsies $(31,94)$. Hypoxia also leads to alteration of miR expression in GC. For example, miR-495 is upregulated under hypoxic conditions in two gastric cell lines, SNU5 and SNU484 (66), and methylation of corresponding promoter 


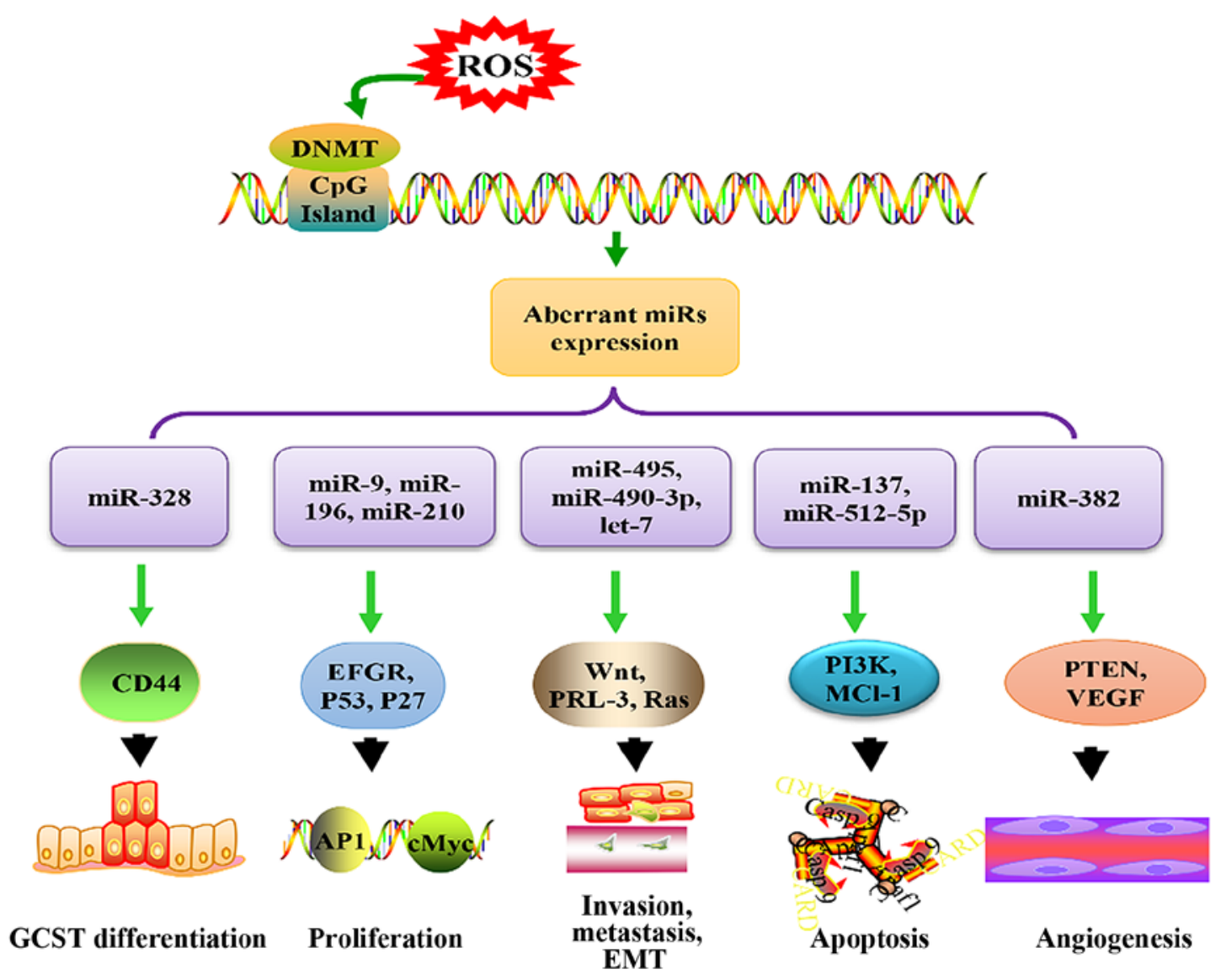

Figure 2. OS-related miRs in development of GC. ROS affect changes in DNMT, thereby contributing to aberrant miR expression. In GC, targets of miRs are involved in gastric cancer stem cell differentiation through CD44, the proliferation of GC through the VEGF signaling pathway, cell cycle regulation through p53, the EMT though the Wnt signaling pathway, apoptosis by the PI3K signaling pathway, and invasion and metastasis through PRL-3.

region contributes to dysregulation of miR-495 in GC. Following inhibition by DNMT1 and Zeste homolog 2 (EZH2), a repressed level of miR-200b/a/429 leads to progression of GC (95). The methylation-mediated silencing of miR-9 family in a GC cell line and the patient specimens was confirmed by combined bisulfate restriction analysis (COBRA) (96). Importantly, treating cells with 5-aza-2'-deoxycytidine (5-aza-CdR) reverses this action. Similarly, methylation of miR-137 gradually increases in normal gastric tissue, chronic gastritis, and GC tissue (97), and treatment of GC cell lines with 5-aza-CdR and 4-phenylbutyric acid (PBA) activates previously silenced miR-512-5p, causing its raised levels to induce cell apoptosis (98). Collectively, miRs are frequently dysregulated in GC (Table III). Interestingly, levels of most miRs are decreased by hypomethylation, but only two miRs, namely miR-196b and miR-127, have been identified to be elevated by hypomethylation in GC $(99,100)$.

Actually, ROS-mediated deregulation of DNA methylation is quite an important aspect of biological role of ROS. ROS-mediated elevation of 8-OHdG in $\mathrm{CpG}$ island is one of the major mechanism of ROS-mediated hypomethylation, however, some form of ROS induced DNA damage also stimulate DNA methylation of specific loci. DNA hypermethylation of promoter region of genes is known to result in gene silencing, whereas hypomethylation contributes to increased gene expression. In GC, ROS induce expression of HIF-1 $\alpha$ (19), which increases expression of DNMT enzymes DNMT1 and DNMT3B, resulting in gene silencing through gene hypermethylation (108). Interestingly, HIF-1 $\alpha$ can also result in hypomethylation of genes by regulating MAT1A/MAT2A switch (109). By contrast, expression of miRs could also be modulated by histone deacetylases (HDACs). For example, miR-466 h-5p is elevated when histone deacetylation is inhibited by glucose deprivation-induced OS (110).

In conclusion, this review infers that in GC, ROS lead to changes in DNMT, which results in methylation changes in promoter region of miR genes that play roles in development of GC through inhibition of their targets and related signaling pathways (Fig. 2).

\section{Conclusion}

We summarized changes of OS as well as miRs and analyzed their function in gastric carcinogenesis. We conclude that ROS and parts of miRs exhibit overlapped characters in gastric carcinogenesis. Given that ROS mediate expression of miRs through epigenetic mechanism, we predict miRs serve as a bridge between ROS and gastric cancer. ROS are the driving force for gastric carcinogenesis. In both human and mouse gastric cancer models, ROS triggered crucial signal pathways and vital molecules such as Wnt, ERK, P53, and miRs to induce initiation and development of GC. In Hp-positive GC patients as well as Hp evoked mouse model of GC, ROS are also confirmed dysfunctional. While, we must accept that in 
treatment of GC, most drugs function through ROS-activated apoptosis of tumor cells, and some researchers found antioxidant can promote progress of cancer cells. Activities of ROS levels were dependent on cancer cells. How to define the threshold of ROS may be an important approach to identify their function in cancer cells. miRs are hot topics in cancer research. Diverse miRs change in GC making them hard to be specific targets in treatment of GC. However, detection of miRs in body fluid and tissues will be a treatment reaction or prognostic factor. miR expression profiling studies make it possible for us to probe miR change in different tissues or body fluid. Despite the encouraging prospect, we are still faced with many difficulties in the fields of OS-induced miRs in GC, tumor-related miRs, signaling pathway network between OS and gastric cancer and interaction between them. Expression of miRs presents tissue, time, and space specificity and can be affected by a variety of factors, which makes it hard to identify a consistent miRNA signature with high specificity for diagnosis and prognosis purpose. Furthermore, miRs exert a limited role in complex gene regulation network and modulate expression of multiple genes, suggesting complexity of miR function and both the potentially limited and undeliberate effect of therapy targeted to a limited number of miRs.

\section{Acknowledgements}

This study was supported by Natural Science Foundation of Shaanxi Province (no. 99SM50), National Natural Science Foundation of China (no. 81171288) for the research of oxidative stress and depression, and the Fundamental Research Funds for the Central Universities (no. 0601-08143036).

\section{References}

1. Riquelme I, Saavedra K, Espinoza JA, Weber H, García P, Nervi B, Garrido M, Corvalán AH, Roa JC and Bizama C: Molecular classification of gastric cancer: Towards a pathwaydriven targeted therapy. Oncotarget 6: 24750-24779, 2015.

2. Wei YC, Zhou FL, He DL, Bai JR, Ding H, Wang XY and Nan KJ: Oxidative stress in depressive patients with gastric adenocarcinoma. Int J Neuropsychopharmacol 12: 1089-1096, 2009.

3. Chaturvedi R, de Sablet T, Asim M, Piazuelo MB, Barry DP, Verriere TG, Sierra JC, Hardbower DM, Delgado AG, Schneider BG, et al: Increased Helicobacter pylori-associated gastric cancer risk in the Andean region of Colombia is mediated by spermine oxidase. Oncogene 34: 3429-3440, 2015.

4. Ishimoto $T$, Sugihara $H$, Watanabe $M$, Sawayama $H$, Iwatsuki $M$, Baba Y, Okabe H, Hidaka K, Yokoyama N, Miyake K, et al: Macrophage-derived reactive oxygen species suppress miR-328 targeting CD44 in cancer cells and promote redox adaptation. Carcinogenesis 35: 1003-1011, 2014.

5. Benfey PN: Molecular biology: microRNA is here to stay. Nature 425: 244-245, 2003.

6. Song JH and Meltzer SJ: MicroRNAs in pathogenesis, diagnosis, and treatment of gastroesophageal cancers. Gastroenterology 143: 35-47.e2, 2012.

7. Wang L, Tang ZP, Zhao W, Cong BH, Lu JQ, Tang XL, Li XH, Zhu XY and Ni X: MiR-22/Sp-1 links estrogens with the up-regulation of cystathionine $\gamma$-lyase in myocardium, which contributes to estrogenic cardioprotection against oxidative stress. Endocrinology 156: 2124-2137, 2015.

8. Xiao Y, Yan W, Lu L, Wang Y, Lu W, Cao Y and Cai W: p38/p53/ miR-200a-3p feedback loop promotes oxidative stress-mediated liver cell death. Cell Cycle 14: 1548-1558, 2015.

9. Xu L, Ziegelbauer J, Wang R, Wu WW, Shen RF, Juhl H, Zhang Y and Rosenberg A: Distinct profiles for mitochondrial t-RNAs and small nucleolar RNAs in locally invasive and metastatic colorectal cancer. Clin Cancer Res 22: 773-784 2016.
10. Maya-Mendoza A, Ostrakova J, Kosar M, Hall A, Duskova P, Mistrik M, Merchut-Maya JM, Hodny Z, Bartkova J, Christensen C, et al: Myc and Ras oncogenes engage different energy metabolism programs and evoke distinct patterns of oxidative and DNA replication stress. Mol Oncol 9: 601-616, 2015.

11. Zhou F, Shen Q and Claret FX: Novel roles of reactive oxygen species in the pathogenesis of acute myeloid leukemia. J Leukoc Biol 94: 423-429, 2013.

12. Jeon SM, Chandel NS and Hay N: AMPK regulates NADPH homeostasis to promote tumour cell survival during energy stress. Nature 485: 661-665, 2012.

13. Farías JG, Herrera EA, Carrasco-Pozo C, Sotomayor-Zárate R, Cruz G, Morales P and Castillo RL: Pharmacological models and approaches for pathophysiological conditions associated with hypoxia and oxidative stress. Pharmacol Ther 158: 1-23, 2016.

14. Dolado I, Swat A, Ajenjo N, De Vita G, Cuadrado A and Nebreda AR: p38alpha MAP kinase as a sensor of reactive oxygen species in tumorigenesis. Cancer Cell 11: 191-205, 2007.

15. Abu-Alainin W, Gana T, Liloglou T, Olayanju A, Barrera LN, Ferguson R, Campbell F, Andrews T, Goldring C, Kitteringham N, et al: UHRF1 regulation of the Keap1-Nrf2 pathway in pancreatic cancer contributes to oncogenesis. J Pathol 238: 423-433, 2016.

16. Mashimo M, Nishikawa M, Higuchi K, Hirose M, Wei Q, Haque A, Sasaki E, Shiba M, Tominaga K, Watanabe T, et al: Production of reactive oxygen species in peripheral blood is increased in individuals with Helicobacter pylori infection and decreased after its eradication. Helicobacter 11: 266-271, 2006.

17. Mikuni T and Tatsuta M: Production of hydroxyl free radical in the xanthine oxidase system with addition of 1-methyl-3-nitro1-nitrosoguanidine. Free Radic Res 36: 641-647, 2002.

18. Tatsuta M, Iishi H, Baba M, Mikuni T, Narahara H, Uedo N and Yano H: Suppression by iron chelator phenanthroline of sodium chloride-enhanced gastric carcinogenesis induced by N-methylN'-nitro-N-nitrosoguanidine in Wistar rats. Cancer Lett 191: 9-16, 2003.

19. Park JH, Kim TY, Jong HS, Kim TY, Chun YS, Park JW, Lee CT, Jung HC, Kim NK and Bang YJ: Gastric epithelial reactive oxygen species prevent normoxic degradation of hypoxiainducible factor-1alpha in gastric cancer cells. Clin Cancer Res 9: 433-440, 2003.

20. Kannan A, Krishnan A, Ali M, Subramaniam S, Halagowder D and Sivasithamparam ND: Caveolin-1 promotes gastric cancer progression by up-regulating epithelial to mesenchymal transition by crosstalk of signalling mechanisms under hypoxic condition. Eur J Cancer 50: 204-215, 2014.

21. Rath S, Das L, Kokate SB, Pratheek BM, Chattopadhyay S, Goswami C, Chattopadhyay R, Crowe SE and Bhattacharyya A: Regulation of Noxa-mediated apoptosis in Helicobacter pyloriinfected gastric epithelial cells. FASEB J 29: 796-806, 2015.

22. Hao W, Yuan X, Yu L, Gao C, Sun X, Wang D and Zheng Q: Licochalcone A-induced human gastric cancer BGC-823 cells apoptosis by regulating ROS-mediated MAPKs and PI3K/AKT signaling pathways. Sci Rep 5: 10336, 2015.

23. Chen JJ, Huang WC and Chen CC: Transcriptional regulation of cyclooxygenase- 2 in response to proteasome inhibitors involves reactive oxygen species-mediated signaling pathway and recruitment of CCAAT/enhancer-binding protein delta and CREB-binding protein. Mol Biol Cell 16: 5579-5591, 2005.

24. Leone A, Roca MS, Ciardiello C, Terranova-Barberio M, Vitagliano C, Ciliberto G, Mancini R, Di Gennaro E, Bruzzese F and Budillon A: Vorinostat synergizes with EGFR inhibitors in NSCLC cells by increasing ROS via up-regulation of the major mitochondrial porin VDAC1 and modulation of the c-MycNRF2-KEAP1 pathway. Free Radic Biol Med 89: 287-299, 2015.

25. Yuan X, Zhou Y, Wang W, Li J, Xie G, Zhao Y, Xu D and Shen L: Activation of TLR4 signaling promotes gastric cancer progression by inducing mitochondrial ROS production. Cell Death Dis 4: e794, 2013

26. Chaturvedi R, Asim M, Piazuelo MB, Yan F, Barry DP, Sierra JC, Delgado AG, Hill S, Casero RA Jr, Bravo LE, et al: Activation of EGFR and ERBB2 by Helicobacter pylori results in survival of gastric epithelial cells with DNA damage. Gastroenterology 146: 1739-1751, 2014.

27. Ferreira AG, Scherer EB, da Cunha AA, Manfredini V, Biancini GB, Vanzin CS, Vargas CR and Wyse AT: Hyperprolinemia induces DNA, protein and lipid damage in blood of rats: Antioxidant protection. Int J Biochem Cell Biol 54: 20-25, 2014. 
28. Zhou X, Xu G, Yin C, Jin W and Zhang G: Down-regulation of miR-203 induced by Helicobacter pylori infection promotes the proliferation and invasion of gastric cancer by targeting CASK Oncotarget 5: 11631-11640, 2014.

29. Morgan C, Jenkins GJ, Ashton T, Griffiths AP, Baxter JN, Parry EM and Parry JM: Detection of p53 mutations in precancerous gastric tissue. Br J Cancer 89: 1314-1319, 2003.

30. Ishimoto T, Izumi D, Watanabe M, Yoshida N, Hidaka K, Miyake K, Sugihara H, Sawayama H, Imamura Y, Iwatsuki M, et al: Chronic inflammation with Helicobacter pylori infection is implicated in CD44 overexpression through miR-328 suppression in the gastric mucosa. J Gastroenterol 50: 751-757, 2015.

31. Kiga K, Mimuro H, Suzuki M, Shinozaki-Ushiku A, Kobayashi T, Sanada T, Kim M, Ogawa M, Iwasaki YW, Kayo H, et al: Epigenetic silencing of miR-210 increases the proliferation of gastric epithelium during chronic Helicobacter pylori infection. Nat Commun 5: 4497, 2014.

32. Bhattacharyya A, Chattopadhyay R, Mitra S and Crowe SE: Oxidative stress: An essential factor in the pathogenesis of gastrointestinal mucosal diseases. Physiol Rev 94: 329-354, 2014

33. Niu Y, DesMarais TL, Tong Z, Yao Y and Costa M: Oxidative stress alters global histone modification and DNA methylation. Free Radic Biol Med 82: 22-28, 2015.

34. Salminen A, Haapasalo A, Kauppinen A, Kaarniranta K, Soininen $\mathrm{H}$ and Hiltunen M: Impaired mitochondrial energy metabolism in Alzheimer's disease: Impact on pathogenesis via disturbed epigenetic regulation of chromatin landscape. Prog Neurobiol 131: 1-20, 2015.

35. Shi Q, Zhang W, Guo S, Jian Z, Li S, Li K, Ge R, Dai W, Wang G, Gao T, et al: Oxidative stress-induced overexpression of miR-25: The mechanism underlying the degeneration of melanocytes in vitiligo. Cell Death Differ 23: 496-508, 2016

36. Fierro-Fernández M, Busnadiego Ó, Sandoval P, Espinosa-Díez C, Blanco-RuizE, Rodríguez M, Pian H, Ramos R, López-Cabrera M, García-Bermejo ML, et al: miR-9-5p suppresses pro-fibrogenic transformation of fibroblasts and prevents organ fibrosis by targeting NOX4 and TGFBR2. EMBO Rep 16: 1358-1377, 2015.

37. Ando Y and Leung AK: Does an emergency visit to the ER make microRNAs stronger during stress? Mol Cell 52: 1-3, 2013.

38. Upton JP, Wang L, Han D, Wang ES, Huskey NE, Lim L, Truitt M, McManus MT, Ruggero D, Goga A, et al: IRE1 $\alpha$ cleaves select microRNAs during ER stress to derepress translation of proapoptotic Caspase-2. Science 338: 818-822, 2012.

39. Sturchio E, Colombo T, Carucci N, Meconi C, Boccia P and Macino G: Molecular biomarkers in workers and population exposed to inorganic arsenic: Preliminary study in vitro. G Ital Med Lav Ergon 34 (Suppl): 678-681, 2012 (In Italian)

40. Rebucci M, Sermeus A, Leonard E, Delaive E, Dieu M, Fransolet M, Arnould T and Michiels C: miRNA-196b inhibits cell proliferation and induces apoptosis in HepG2 cells by targeting IGF2BP1. Mol Cancer 14: 79, 2015.

41. Blick C, Ramachandran A, McCormick R, Wigfield S, Cranston D, Catto J and Harris AL: Identification of a hypoxiaregulated miRNA signature in bladder cancer and a role for miR-145 in hypoxia-dependent apoptosis. Br J Cancer 113: 634-644, 2015.

42. Kwon JE, Kim BY, Kwak SY, Bae IH and Han YH: Ionizing radiation-inducible microRNA miR-193a-3p induces apoptosis by directly targeting Mcl-1. Apoptosis 18: 896-909, 2013.

43. Kwak SY, Kim BY, Ahn HJ, Yoo JO, Kim J, Bae IH and Han YH: Ionizing radiation-inducible miR-30e promotes glioma cell invasion through EGFR stabilization by directly targeting CBL-B. FEBS J 282: 1512-1525, 2015.

44. Seok JK, Lee SH, Kim MJ and Lee YM: MicroRNA-382 induced by HIF- $1 \alpha$ is an angiogenic miR targeting the tumor suppressor phosphatase and tensin homolog. Nucleic Acids Res 42: 8062-8072, 2014.

45. Tu H, Sun H, Lin Y, Ding J, Nan K, Li Z, Shen Q and Wei Y: Oxidative stress upregulates PDCD4 expression in patients with gastric cancer via miR-21. Curr Pharm Des 20: 1917-1923, 2014.

46. Polytarchou C, Iliopoulos D, Hatziapostolou M, Kottakis F, Maroulakou I, Struhl K and Tsichlis PN: Akt2 regulates all Akt isoforms and promotes resistance to hypoxia through induction of miR-21 upon oxygen deprivation. Cancer Res 71: 4720-4731, 2011.

47. Shi Z, Zhang J, Qian X, Han L, Zhang K, Chen L, Liu J, Ren Y, Yang M, Zhang A, et al: AC1MMYR2, an inhibitor of dicer-mediated biogenesis of Oncomir miR-21, reverses epithelial-mesenchymal transition and suppresses tumor growth and progression. Cancer Res 73: 5519-5531, 2013.
48. Gu H, Yu J, Dong D, Zhou Q, Wang J-Y, Fang S and Yang P: High glucose-repressed CITED2 expression through miR-200b triggers the unfolded protein response and endoplasmic reticulum stress. Diabetes 65: 149-163, 2016.

49. Feng Y, Wang L, Zeng J, Shen L, Liang X, Yu H, Liu S, Liu Z, Sun Y, Li W, et al: FoxM1 is overexpressed in Helicobacter pylori-induced gastric carcinogenesis and is negatively regulated by miR-370. Mol Cancer Res 11: 834-844, 2013.

50. Serguienko A, Grad I, Wennerstrøm AB, Meza-Zepeda LA, Thiede B, Stratford EW, Myklebost O and Munthe E: Metabolic reprogramming of metastatic breast cancer and melanoma by let-7a microRNA. Oncotarget 6: 2451-2465, 2015.

51. Lee S, Yun I, Ham O, Lee SY, Lee CY, Park JH, Lee J, Seo HH, Choi E and Hwang KC: Suppression of miR-181a attenuates $\mathrm{H}_{2} \mathrm{O}_{2}$-induced death of mesenchymal stem cells by maintaining hexokinase II expression. Biol Res 48: 45, 2015.

52. Chen Z, Wen L, Martin M, Hsu CY, Fang L, Lin FM, Lin TY, Geary MJ, Geary GG, Zhao Y, et al: Oxidative stress activates endothelial innate immunity via sterol regulatory element binding protein 2 (SREBP2) transactivation of microRNA-92a. Circulation 131: 805-814, 2015.

53. Meseguer S, Martínez-Zamora A, García-Arumí E, Andreu AL and Armengod ME: The ROS-sensitive microRNA-9/9* controls the expression of mitochondrial tRNA-modifying enzymes and is involved in the molecular mechanism of MELAS syndrome. Hum Mol Genet 24: 167-184, 2015.

54. Chen M, Ma G, Yue Y, Wei Y, Li Q, Tong Z, Zhang L, Miao G and Zhang J: Downregulation of the miR-30 family microRNAs contributes to endoplasmic reticulum stress in cardiac muscle and vascular smooth muscle cells. Int J Cardiol 173: 65-73, 2014.

55. Rahman M, Lovat F, Romano G, Calore F, Acunzo M, Bell EH and Nana-Sinkam P: miR-15b/16-2 regulates factors that promote p53 phosphorylation and augments the DNA damage response following radiation in the lung. J Biol Chem 289: 26406-26416, 2014.

56. Zhao L, Tang M, Hu Z, Yan B, Pi W, Li Z, Zhang J, Zhang L, Jiang W, Li G, et al: miR-504 mediated down-regulation of nuclear respiratory factor 1 leads to radio-resistance in nasopharyngeal carcinoma. Oncotarget 6: 15995-16018, 2015.

57. Luo EC, Chang YC, Sher YP, Huang WY, Chuang LL, Chiu YC, Tsai MH, Chuang EY and Lai LC: MicroRNA-769-3p downregulates NDRG1 and enhances apoptosis in MCF-7 cells during reoxygenation. Sci Rep 4: 5908, 2014.

58. Li BS, Zuo QF, Zhao YL, Xiao B, Zhuang Y, Mao XH, Wu C, Yang SM, Zeng H, Zou QM, et al: MicroRNA-25 promotes gastric cancer migration, invasion and proliferation by directly targeting transducer of ERBB2, 1 and correlates with poor survival. Oncogene 34: 2556-2565, 2015.

59. Bandres E, Bitarte N, Arias F, Agorreta J, Fortes P, Agirre X, Zarate R, Diaz-Gonzalez JA, Ramirez N, Sola JJ, et al: microRNA-451 regulates macrophage migration inhibitory factor production and proliferation of gastrointestinal cancer cells. Clin Cancer Res 15: 2281-2290, 2009.

60. Witalison EE, Cui X, Causey CP, Thompson PR and Hofseth LJ: Molecular targeting of protein arginine deiminases to suppress colitis and prevent colon cancer. Oncotarget 6: 36053-36062, 2015.

61. Lin Y, Li D, Liang Q, Liu S, Zuo X, Li L, Sun X, Li W, Guo M and Huang Z: miR-638 regulates differentiation and proliferation in leukemic cells by targeting cyclin-dependent kinase 2 . J Biol Chem 290: 1818-1828, 2015.

62. Zhu Z, Xu Y, Zhao J, Liu Q, Feng W, Fan J and Wang P: miR-367 promotes epithelial-to-mesenchymal transition and invasion of pancreatic ductal adenocarcinoma cells by targeting the Smad7-TGF- $\beta$ signalling pathway. Br J Cancer 112: 1367-1375, 2015.

63. Liu GT, Chen HT, Tsou HK, Tan TW, Fong YC, Chen PC, Yang WH, Wang SW, Chen JC and Tang CH: CCL5 promotes VEGF-dependent angiogenesis by down-regulating miR-200b through PI3K/Akt signaling pathway in human chondrosarcoma cells. Oncotarget 5: 10718-10731, 2014.

64. Liu Y, Zhang X, Zhang Y, Hu Z, Yang D, Wang C, Guo M and Cai Q: Identification of miRNomes in human stomach and gastric carcinoma reveals miR-133b/a-3p as therapeutic target for gastric cancer. Cancer Lett 369: 58-66, 2015.

65. Liu X, Ge X, Zhang Z, Zhang X, Chang J, Wu Z, Tang W, Gan L, Sun M and Li J: MicroRNA-940 promotes tumor cell invasion and metastasis by downregulating ZNF24 in gastric cancer. Oncotarget 6: 25418-25428, 2015. 
66. Lee SH, Jung YD, Choi YS and Lee YM: Targeting of RUNX3 by miR-130a and miR-495 cooperatively increases cell proliferation and tumor angiogenesis in gastric cancer cells. Oncotarget 6 : 33269-33278, 2015.

67. Yanaka Y, Muramatsu T, Uetake H, Kozaki K and Inazawa J: miR-544a induces epithelial-mesenchymal transition through the activation of WNT signaling pathway in gastric cancer. Carcinogenesis 36: 1363-1371, 2015 .

68. Shi DB, Wang YW, Xing AY, Gao JW, Zhang H, Guo XY and Gao P: C/EBP $\alpha$-induced miR-100 expression suppresses tumor metastasis and growth by targeting ZBTB7A in gastric cancer. Cancer Lett 369: 376-385, 2015.

69. Du Y, Xu Y, Ding L, Yao H, Yu H, Zhou T and Si J: Downregulation of miR-141 in gastric cancer and its involvement in cell growth. J Gastroenterol 44: 556-561, 2009.

70. Li Z, Cao Y, Jie Z, Liu Y, Li Y, Li J, Zhu G, Liu Z, Tu Y, Peng G, et al: miR-495 and miR-551a inhibit the migration and invasion of human gastric cancer cells by directly interacting with PRL-3. Cancer Lett 323: 41-47, 2012.

71. Sun M, Liu XH, Li JH, Yang JS, Zhang EB, Yin DD, Liu ZL, Zhou J, Ding Y, Li SQ, et al: MiR-196a is upregulated in gastric cancer and promotes cell proliferation by downregulating p27 (kip1). Mol Cancer Ther 11: 842-852, 2012.

72. Zhao XD, Lu YY, Guo H, Xie HH, He LJ, Shen GF, Zhou JF, Li T, Hu SJ, Zhou L, et al: MicroRNA-7/NF- $\mathrm{kB}$ signaling regulatory feedback circuit regulates gastric carcinogenesis. J Cell Biol 210: 613-627, 2015

73. Kong WQ, Bai R, Liu T, Cai CL, Liu M, Li X and Tang H: MicroRNA-182 targets cAMP-responsive element-binding protein 1 and suppresses cell growth in human gastric adenocarcinoma. FEBS J 279: 1252-1260, 2012.

74. Zheng L, Pu J, Qi T, Qi M, Li D, Xiang X, Huang K and Tong Q miRNA-145 targets v-ets erythroblastosis virus E26 oncogene homolog 1 to suppress the invasion, metastasis, and angiogenesis of gastric cancer cells. Mol Cancer Res 11: 182-193, 2013.

75. Yang G, Gong Y, Wang Q, Wang Y and Zhang X: The role of miR-100-mediated Notch pathway in apoptosis of gastric tumor cells. Cell Signal 27: 1087-1101, 2015.

76. Zheng B, Liang L, Huang S, Zha R, Liu L, Jia D, Tian Q, Wang Q, Wang C, Long Z, et al: MicroRNA-409 suppresses tumour cell invasion and metastasis by directly targeting radixin in gastric cancers. Oncogene 31: 4509-4516, 2012.

77. Li C, Nie H, Wang M, Su L, Li J, Yu B, Wei M, Ju J, Yu Y, Yan M, et al: MicroRNA-409-3p regulates cell proliferation and apoptosis by targeting PHF10 in gastric cancer. Cancer Lett 320 : 189-197, 2012.

78. Xia J, Wu Z, Yu C, He W, Zheng H, He Y, Jian W, Chen L, Zhang L and Li W: miR-124 inhibits cell proliferation in gastric cancer through down-regulation of SPHK1. J Pathol 227: 470-480, 2012 .

79. Wang M, Li C, Nie H, Lv X, Qu Y, Yu B, Su L, Li J, Chen X, $\mathrm{Ju} \mathrm{J}$, et al: Down-regulated miR-625 suppresses invasion and metastasis of gastric cancer by targeting ILK. FEBS Lett 586: 2382-2388, 2012

80. Gao P, Xing AY, Zhou GY, Zhang TG, Zhang JP, Gao C, Li H and Shi DB: The molecular mechanism of microRNA-145 to suppress invasion-metastasis cascade in gastric cancer. Oncogene 32 491-501, 2013

81. Zhang X, Tang J, Zhi X, Xie K, Wang W, Li Z, Zhu Y, Yang L, $\mathrm{Xu} \mathrm{H}$ and $\mathrm{Xu} \mathrm{Z:} \mathrm{miR-874} \mathrm{functions} \mathrm{as} \mathrm{a} \mathrm{tumor} \mathrm{suppressor} \mathrm{by}$ inhibiting angiogenesis through STAT3/VEGF-A pathway in gastric cancer. Oncotarget 6: 1605-1617, 2015.

82. Huang TH, Wu F, Loeb GB, Hsu R, Heidersbach A, Brincat A Horiuchi D, Lebbink RJ, Mo YY, Goga A, et al: Up-regulation of miR-21 by HER $2 /$ neu signaling promotes cell invasion. J Biol Chem 284: 18515-18524, 2009.

83. Si ML, Zhu S, Wu H, Lu Z, Wu F and Mo YY: miR-21-mediated tumor growth. Oncogene 26: 2799-2803, 2007.

84. Zhu S, Wu H, Wu F, Nie D, Sheng S and Mo YY: MicroRNA-21 targets tumor suppressor genes in invasion and metastasis. Cell Res 18: 350-359, 2008.

85. Wang M, Li C, Yu B, Su L, Li J, Ju J, Yu Y, Gu Q, Zhu Z and Liu B: Overexpressed miR-301a promotes cell proliferation and invasion by targeting RUNX3 in gastric cancer. J Gastroenterol 48: 1023-1033, 2013

86. Li T, Lu YY, Zhao XD, Guo HQ, Liu CH, Li H, Zhou L, Han YN, Wu KC, Nie YZ, et al: MicroRNA-296-5p increases proliferation in gastric cancer through repression of Caudal-related homeobox 1. Oncogene 33: 783-793, 2014.
87. Li X, Zhang Y, Zhang H, Liu X, Gong T, Li M, Sun L, Ji G, Shi Y, Han Z, et al: miRNA-223 promotes gastric cancer invasion and metastasis by targeting tumor suppressor EPB41L3. Mol Cancer Res 9: 824-833, 2011.

88. Cui L, Zhang X, Ye G, Zheng T, Song H, Deng H, Xiao B, Xia T, Yu X, Le Y, et al: Gastric juice microRNAs as potential biomarkers for the screening of gastric cancer. Cancer 119: 1618-1626, 2013

89. Imaoka H, Toiyama Y, Okigami M,, Yasuda H, Saigusa S, Ohi M, Tanaka K, Inoue Y, Mohri Y and Kusunoki M: Circulating microRNA-203 predicts metastases, early recurrence, and poor prognosis in human gastric cancer. Gastric Cancer 19: 744-753, 2016.

90. Taube JH, Malouf GG, Lu E, Sphyris N, Vijay V, Ramachandran PP, Ueno KR, Gaur S, Nicoloso MS, Rossi S, et al: Epigenetic silencing of microRNA-203 is required for EMT and cancer stem cell properties. Sci Rep 3: 2687, 2013

91. Donzelli S, Mori F, Bellissimo T, Sacconi A, Casini B, Frixa T, Roscilli G, Aurisicchio L, Facciolo F, Pompili A, et al: Epigenetic silencing of miR-145-5p contributes to brain metastasis. Oncotarget 6: 35183-35201, 2015.

92. Kang H, Kim C, Lee H, Rho JG, Seo JW, Nam JW, Song WK, Nam SW, Kim W and Lee EK: Downregulation of microRNA362-3p and microRNA-329 promotes tumor progression in human breast cancer. Cell Death Differ 23: 484-495, 2016.

93. He J, Xu Q, Jing Y, Agani F, Qian X, Carpenter R, Li Q, Wang XR, Peiper SS, Lu Z, et al: Reactive oxygen species regulate ERBB2 and ERBB3 expression via miR-199a/125b and DNA methylation. EMBO Rep 13: 1116-1122, 2012.

94. Li P, Shan JX, Chen XH, Zhang D, Su LP, Huang XY, Yu BQ, Zhi QM, Li CL, Wang YQ, et al: Epigenetic silencing of microRNA-149 in cancer-associated fibroblasts mediates prostaglandin E2/interleukin-6 signaling in the tumor microenvironment. Cell Res 25: 588-603, 2015.

95. Ning X, Shi Z, Liu X, Zhang A, Han L, Jiang K, Kang C and Zhang Q: DNMT1 and EZH2 mediated methylation silences the microRNA-200b/a/429 gene and promotes tumor progression. Cancer Lett 359: 198-205, 2015.

96. Tsai KW, Liao YL, Wu CW, Hu LY, Li SC, Chan WC, Ho MR, Lai CH, Kao HW, Fang WL, et al: Aberrant hypermethylation of miR-9 genes in gastric cancer. Epigenetics 6: 1189-1197, 2011

97. Steponaitiene R, Kupcinskas J, Langner C, Balaguer F, Venclauskas L, Pauzas H, Tamelis A, Skieceviciene J, Kupcinskas L, Malfertheiner P, et al: Epigenetic silencing of miR-137 is a frequent event in gastric carcinogenesis. Mol Carcinog 55: 376-386, 2016.

98. Saito Y, Suzuki H, Tsugawa H, Nakagawa I, Matsuzaki J, Kanai Y and Hibi T: Chromatin remodeling at Alu repeats by epigenetic treatment activates silenced microRNA-512-5p with downregulation of Mcl-1 in human gastric cancer cells. Oncogene 28: 2738-2744, 2009.

99. Tsai KW, Hu LY, Wu CW, Li SC, Lai CH, Kao HW, Fang WL and Lin WC: Epigenetic regulation of miR-196b expression in gastric cancer. Genes Chromosomes Cancer 49: 969-980, 2010.

100. Ando T, Yoshida T, Enomoto S, Asada K, Tatematsu M, Ichinose M, Sugiyama T and Ushijima T: DNA methylation of microRNA genes in gastric mucosae of gastric cancer patients: Its possible involvement in the formation of epigenetic field defect. Int J Cancer 124: 2367-2374, 2009.

101. Hayashi Y, Tsujii M, Wang J, Kondo J, Akasaka T, Jin Y, Li W, Nakamura T, Nishida T, Iijima $\mathrm{H}$, et al: CagA mediates epigenetic regulation to attenuate let-7 expression in Helicobacter pylori-related carcinogenesis. Gut 62: 1536-1546, 2013.

102. Zhang EB, Kong R, Yin DD, You LH, Sun M, Han L, Xu TP, Xia R, Yang JS, De W, et al: Long noncoding RNA ANRIL indicates a poor prognosis of gastric cancer and promotes tumor growth by epigenetically silencing of miR-99a/miR-449a. Oncotarget 5: 2276-2292, 2014.

103. Bao W, Fu HJ, Xie QS, Wang L, Zhang R, Guo ZY, Zhao J, Meng YL, Ren XL, Wang T, et al: HER2 interacts with CD44 to up-regulate CXCR4 via epigenetic silencing of microRNA-139 in gastric cancer cells. Gastroenterology 141: 2076-2087.e6, 2011.

104. Shen J, Xiao Z, Wu WK, Wang MH, To KF, Chen Y, Yang W, $\mathrm{Li}$ MS, Shin VY, Tong JH, et al: Epigenetic silencing of miR490-3p reactivates the chromatin remodeler SMARCD1 to promote Helicobacter pylori-induced gastric carcinogenesis. Cancer Res 75: 754-765, 2015. 
105. Li Z, Li D, Zhang G, Xiong J, Jie Z, Cheng H, Cao Y, Jiang M, Lin L, Le Z, et al: Methylation-associated silencing of MicroRNA-335 contributes tumor cell invasion and migration by interacting with RASA1 in gastric cancer. Am J Cancer Res 4: 648-662, 2014

106. Suzuki H, Yamamoto E, Nojima M, Kai M, Yamano HO, Yoshikawa K, Kimura T, Kudo T, Harada E, Sugai T, et al: Methylation-associated silencing of microRNA-34b/c in gastric cancer and its involvement in an epigenetic field defect. Carcinogenesis 31: 2066-2073, 2010.

107. Kurashige J, Mima K, Sawada G, Takahashi Y, Eguchi H, Sugimachi K, Mori M, Yanagihara K, Yashiro M, Hirakawa K, et al: Epigenetic modulation and repression of miR-200b by cancer-associated fibroblasts contribute to cancer invasion and peritoneal dissemination in gastric cancer. Carcinogenesis 36 : 133-141, 2015.
108. Watson CJ, Collier P, Tea I, Neary R, Watson JA, Robinson C, Phelan D, Ledwidge MT, McDonald KM, McCann A, et al: Hypoxia-induced epigenetic modifications are associated with cardiac tissue fibrosis and the development of a myofibroblastlike phenotype. Hum Mol Genet 23: 2176-2188, 2014.

109. Frau M, Feo F and Pascale RM: Pleiotropic effects of methionine adenosyltransferases deregulation as determinants of liver cancer progression and prognosis. J Hepatol 59: 830-841, 2013.

110. Druz A, Betenbaugh M and Shiloach J: Glucose depletion activates mmu-miR-466h-5p expression through oxidative stress and inhibition of histone deacetylation. Nucleic Acids Res 40: 7291-7302, 2012. 